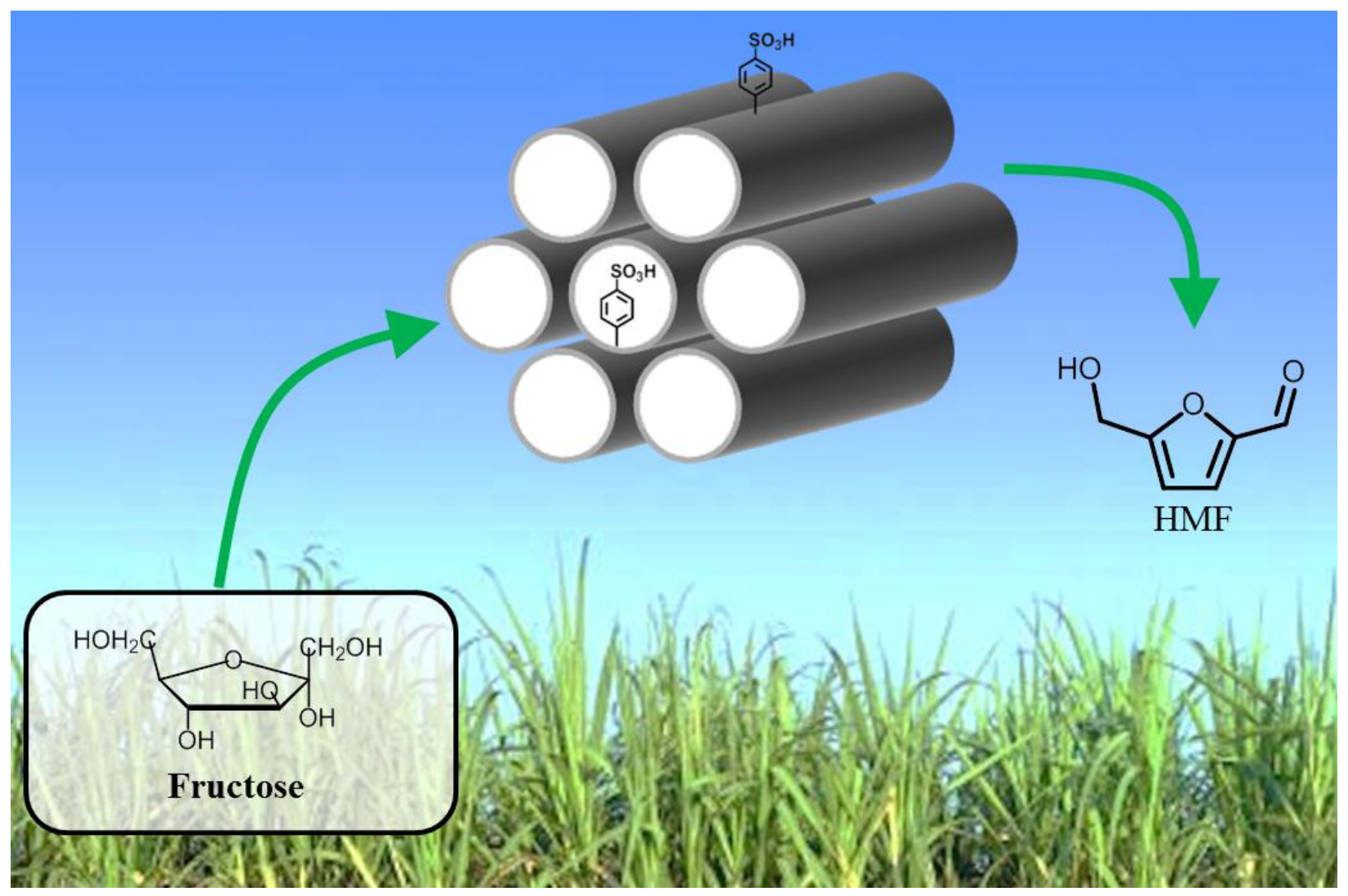




\title{
Acid-Functionalized Mesoporous Carbons for the continuous production of 5-hydroxymethylfurfural
}

\author{
Jean Marcel R. Gallo, ${ }^{1,2 \ddagger}$ Ricardo Alamillo, ${ }^{1 \ddagger}$ James A. Dumesic ${ }^{1 *}$
}

${ }^{1}$ Department of Chemical and Biological Engineering, University of Wisconsin, Madison, Wisconsin 53706-1607, United States.

${ }^{2}$ Department of Chemistry, Federal University of São Carlos, SP, Brazil.

\begin{abstract}
The stability of solid acid catalysts is essential in the development of sustainable biomass conversion processes. Herein, we study the activity and stability of acid-functionalized periodic mesoporous carbons (CMK-3 and CMK-5) for the continuous production of 5-hydroxymethylfurfural from fructose. The acid-functionalized mesoporous carbon catalysts show comparable selectivities and turnover frequency (TOF) to that of propylsulfonic acid functionalized SBA-15. However, the firstorder deactivation rate coefficient of the carbon-based materials are up to 60 times more stable than that for the acid-functionalized SBA-15 catalyst and up to 3 times more stable than commercial Nafion SAC-13. Of the catalysts studied, phenylsulfonic acid CMK-5 showed both the highest TOF for HMF production and lowest deactivation rate coefficient.
\end{abstract}

KEYWORDS. Mesoporous carbon; 5-Hydroxymethylfurfural; Biomass conversion; Heterogeneous Catalysis; Deactivation.

\section{Corresponding Author}

*jdumesic@wisc.edu (J.A. Dumesic)

\section{Author Contributions}

All authors have given approval to the final version of the manuscript. / $\$$ These authors contributed equally. 


\section{Introduction}

The rising demand and diminishing sources of petroleum for the production of fuels and chemicals have motivated the search for an alternative carbon source. Lignocellulosic biomass is the most abundant renewable source of carbon in nature and can provide a route for the sustainable production of fuels and chemicals. For example, the acid catalyzed dehydration of fructose produces 5-hydroxymethylfurfural (HMF), considered one of the top value added chemicals obtained from biomass [1, 2]. Various homogeneous and heterogeneous Brønsted acid catalysts have shown to be active for HMF production from fructose [3-12]. However, homogeneous acids have major technoeconomic challenges, such as reactor corrosion, effluent separation, and issues with catalyst recycling. These problems can be addressed by replacing homogeneous catalysts with heterogeneous catalysts. However, current heterogeneous acid catalysts suffer from acid-site leaching and coke deposition, which lead to rapid deactivation. Both an active and stable solid acid catalyst must be developed for the sustainable development of biomass conversion processes.

Metal oxides and zeolites are the most used catalysts in chemical industry [13, 14], and, hence, these materials are natural candidates for solid acid catalysts in fructose dehydration. However, a benchmark study determined that sulfonic acid functionalized catalysts are both the most selective and have highest reaction rate for HMF production from fructose of the selected solid acid catalysts [15]. Recently, it was reported that propylsulfonic acid functionalized mesoporous silica SBA-15 ( $\left.\mathrm{pSO}_{3} \mathrm{H}-\mathrm{SBA}-15\right)$ presents outstanding performance for $\mathrm{HMF}$ production from fructose in a 4:1 THF:water (w:w) monophasic solvent [4]. However, SBA-15 has poor hydrothermal stability and had a high deactivation rate, mainly due to reversible acid site leaching.[16] To overcome this problem, a catalyst was synthesized [16] using ethane-bridged SBA-15-like Periodic Mesoporous Organosilicas (PMOs) containing propylsulfonic acid functionalities, and this material showed a first-order deactivation rate coefficient almost four times lower than $\mathrm{pSO}_{3} \mathrm{H}-\mathrm{SBA}-15$ for HMF production.

The major challenge in the long-term stability of sulfonic/sulfated silica or metal oxides is the oxygen that mediates the anchoring of the functional group in the support, making the material susceptible to hydrolysis [16, 17]. Carbon can be a robust alternative for these supports, since functional groups can be anchored through C-C and C-S bonds that are not easily hydrolyzed. In this work, we study the activity and deactivation of periodic mesoporous carbons modified with sulfonic and organosulfonic acid groups for the continuous production of HMF from fructose, using 4:1 THF:water (w:w) as a solvent. Shanks 
et. al. have reported hydrothermal stability of carbon based acid catalysts previously with extensive focus on the solid state NMR characterization of the carbon catalysts and its' hydrothermal deactivation [18]. However, there are few reports that investigate both the continuous production of HMF and quantify catalyst deactivation [16].

\section{Methods}

\subsection{Catalyst Synthesis}

The synthetic approaches for acid-functionalized mesoporous carbons are shown in Figure 1. CMK-3 and CMK-5 were synthesized based on previous reports [19, 20], however, pyrolysis was carried out at $1273 \mathrm{~K}$ under helium flow. The carbon functionalization reaction was based on the method reported by Wang et al. [21]. First, a solution of $0.075 \mathrm{~mol}$ of p-sulfanilic acid or 4-Amino-1naphthalenesulfonic acid in $750 \mathrm{~mL}$ of $1 \mathrm{~mol} \mathrm{~L}^{-1}$ aqueous $\mathrm{HCl}$ was prepared. The solution was cooled to 276-278 $\mathrm{K}$ followed by the dropwise addition of $82.5 \mathrm{~mL}$ of $1 \mathrm{~mol} \mathrm{~L}^{-1}$ aqueous $\mathrm{NaNO}_{2}$. Then, $1.2 \mathrm{~g}$ of the carbon support was added and the dispersion was stirred for $5 \mathrm{~h}$ at $3-5^{\circ} \mathrm{C}$. Finally, the material was filtered and washed thoroughly with water. The functionalization reaction mechanism involves the in situ formation of a diazonium compound that binds to the carbon support through a C-C bond. Throughout this synthesis method, CMK-3 was functionalized with phenylsulfonic acid (PSA) or naphthalenesulfonic acid (NSA) and CMK-5 was functionalized with PSA. CMK-3 was also functionalized with sulfonic acid groups by treatment with sulfuric acid [22]. 


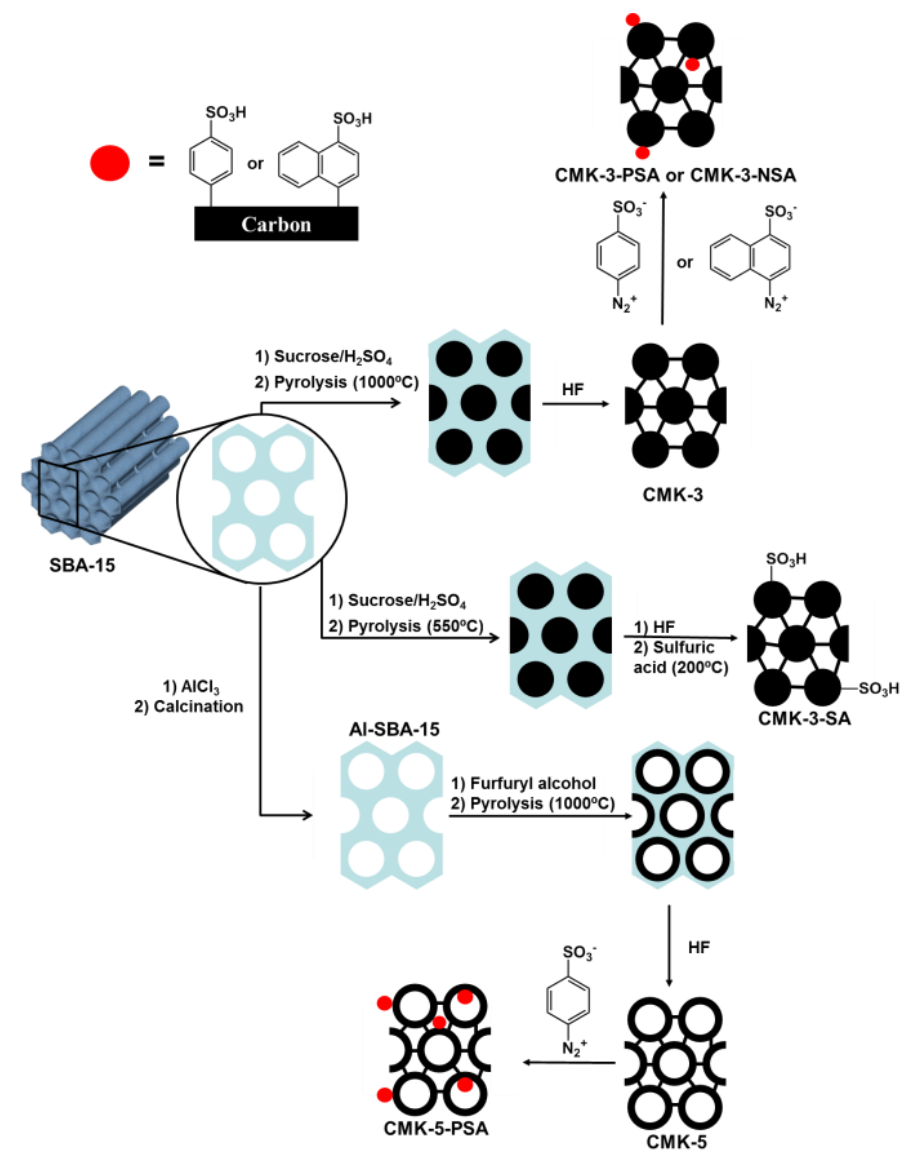

Figure 1. Preparation route for the acid mesoporous carbons.

\subsection{Catalyst Reaction Studies}

The activity and stability of the CMK-3 and CMK-5 catalysts were tested in the dehydration of fructose to $\mathrm{HMF}$ using a $1 / 4$ inch and $1 / 2$ inch diameter fixed bed flow reactor, respectively. For comparison, the mesoporous silica pSO3H-SBA-15 prepared as reported by Scott and co-workers [23], and commercially available Nafion SAC-13 (Nafion immobilized in a silica matrix[24]) were used. The reactor design and reaction conditions for both the $1 / 4$ inch and $1 / 2$ inch diameter fixed bed reactors were identical to the previous reported were used at a constant acid molar loading [16]. The feed consisted of $2 \mathrm{wt} \%$ fructose in a 4:1 THF:water solvent. The presence of THF was shown previously to enhance the HMF selectivity compared to pure water and other organic solvents [25]. However, a fraction of water is required to achieve the complete dissolution of the monosaccharide in the feed mixture. Furthermore, since fructose is produced in aqueous solution, in real process conditions, water is inevitable. Therefore, it is important to study the catalyst performance in the presence of water. 
Product analysis was done using a high pressure liquid chromatography (HPLC) analyses were carried out using a Waters e2695 HPLC system equipped with a 2998 UV-Vis photodiode array detector and a 2414 refractive index detector. In a typical experiment, fructose and HMF were separated on an Aminex HPX-87P column (Biorad) at $358 \mathrm{~K}$, using Milli-Q water as the mobile phase at a flow rate of $0.6 \mathrm{~mL} \mathrm{~min}{ }^{-1}$. HMF concentration was determined using the UV detector $(320 \mathrm{~nm})$, while all other species were monitored using the refractive index detector (maintained at $323 \mathrm{~K}$ ).

\subsection{Catalyst Characterization}

Powder X-ray diffraction (XRD) patterns were collected from 0.6 to $4.0^{\circ}$ [20], using a Panalytical MRD PRO diffractometer with $\mathrm{Cu} \mathrm{K \alpha}$ radiation $\left(0.02^{\circ}\right.$ resolution). $\mathrm{N}_{2}$ adsorption/desorption measurements were performed on a Micromeritics ASAP 2020 system.

The acid sites quantification was carried out by potentiometric titration using an auto titrator Metrohm 848 Titrino Plus leaded with a $0.01 \mathrm{~mol} \mathrm{~L}^{-1}$ standardized $\mathrm{NaOH}$ solution.

\section{Results and Discussion}

\subsection{Catalyst Characterization Studies}

The X-ray diffactograms (XRD) for the functionalized CMK-3 and CMK-5 are presented in Figure 2. Similar to their parent material (SBA-15), CMK3 and CMK-5 contain both the hexagonal pores array and the associated XRD patterns. The expected peaks are assigned to the (100) (most intense), (110), and (200) Miller indices which appear at relative $2 \theta$ values of $X,(\sqrt{ } 3) X$, and $2 X$, respectively. CMK-3 and CMK-5 modified with PSA (Figure 2a and d) and CMK-3-NSA (Figure 2b) present the three expected XRD peaks, which indicates good organization of the pores and long range ordering. On the other hand, the CMK-3-SA XRD diffractogram (Figure 1c) presents only a broader peak related to the (100) Miller index, indicating a large range of unit cell sizes.

The acid sites loading in the samples were determined by potentiometric titration using a 0.01

mol L $\mathrm{L}^{-1}$ sodium hydroxide solution,[26] and the results are shown in Table 1. The samples had an acid site loading between 0.90 and $1.25 \mathrm{mmol} \mathrm{g}^{-1}$. 


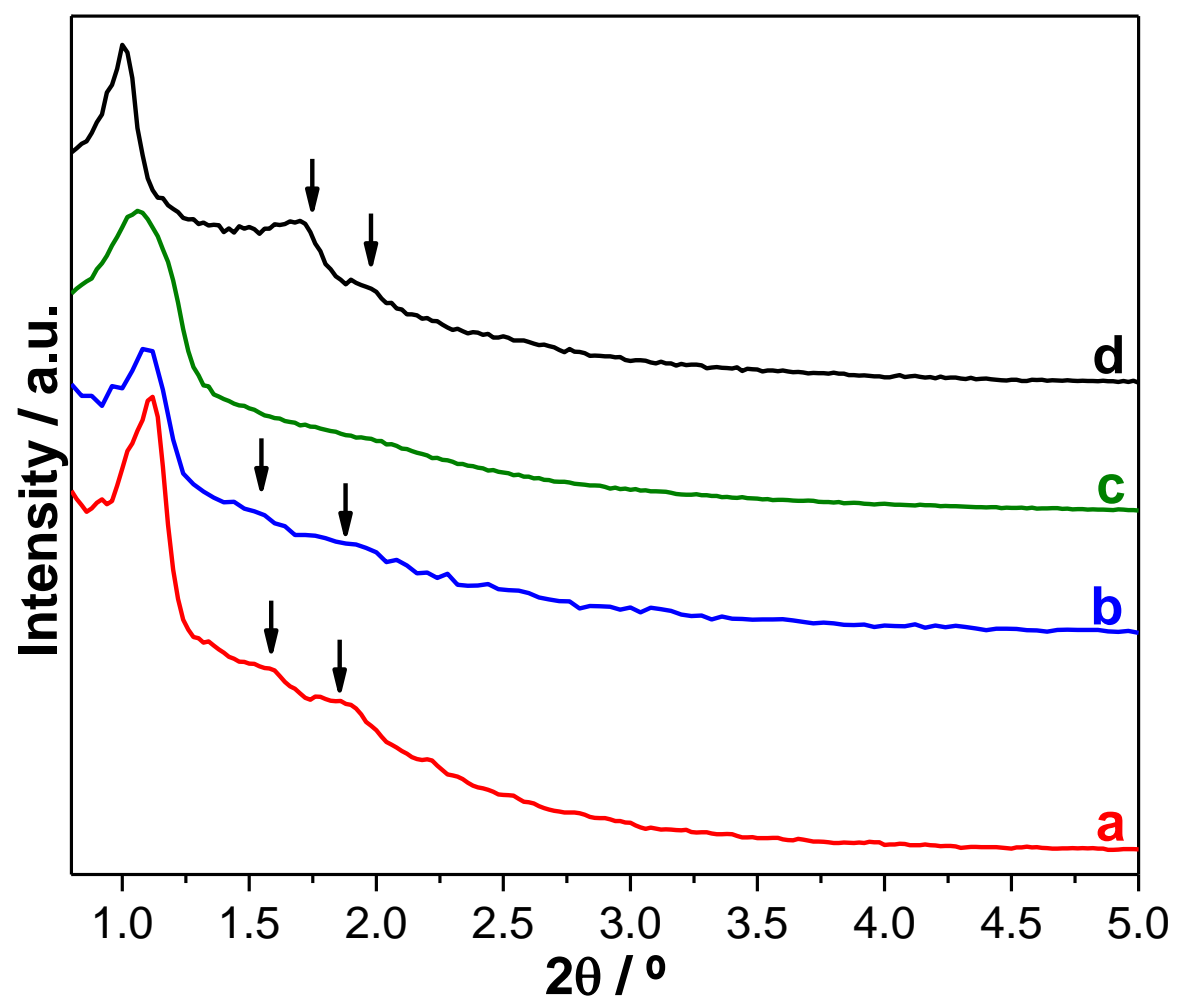

Figure 2. X-ray diffractograms for (a) CMK-3-PSA, (B) CMK-3-NSA, (C) CMK-3-SA, (d) CMK-5PSA. Arrows indicate peaks assigned to (110) and (200) planes.

The surface area and porosity of the samples were determined by nitrogen physisorption at $77 \mathrm{~K}$ and are shown in Table 1. CMK-3-NSA presents a slightly lower surface area and smaller pore sizes than CMK-3-PSA, which is expected since NSA is a bulkier functional group. Due to the absence of bulk functional groups, CMK-3-SA has the highest surface area and largest pore sizes of the above mentioned CMK-3 materials. CMK-5-PSA displays a surface area higher than CMK-3-PSA, since its structure is formed by pipes, which have internal and external surfaces. CMK-5 has a bimodal pore structure, in which the larger pores are assigned to the voids inside the nanopipes, whereas the smaller pores are due to the voids between the nanopipes (similar to CMK-3).[27, 28] 
Table 1. Acids site loading, surface area, and pore sizes for CMK-3 and CMK-5 catalysts.

\begin{tabular}{|c|c|c|c|}
\hline Catalyst & {$\left[\mathbf{H}^{+}\right]^{\mathbf{a}} / \mathbf{~ m m o l ~ \mathbf { g } ^ { - \mathbf { 1 } }}$} & $\mathbf{S}_{\mathbf{B E T}}^{\mathbf{b}} / \mathbf{m}^{\mathbf{2}} \mathbf{g}^{-\mathbf{1}}$ & $\mathbf{W}_{\mathbf{B J H}}{ }^{\mathbf{c}} / \mathbf{n m}$ \\
\hline CMK-3-PSA & 1.21 & 480 & 2.80 \\
\hline CMK-3-NSA & 0.97 & 420 & 2.58 \\
\hline CMK-3-SA & 1.25 & 1368 & 3.72 \\
\hline CMK-5-PSA & 0.90 & 616 & $2.67 \& 3.38$ \\
\hline
\end{tabular}

${ }^{\mathrm{a}}$ determined by potentiometric titration; ${ }^{\mathrm{b}}$ surface area obtained by BET method; ${ }^{\mathrm{c}}$ pore size obtained by BJH method using KJS correction, except for CMK-5, in which no correction was used, as recommended in literature [27].

\subsection{Catalyst Reaction Kinetics Studies}

A comparison of catalyst performance at higher fructose conversions is shown in Figure 3 . The CMK-3 and CMK-5 based catalysts demonstrated comparable selectivities to HMF (71-74 \%) at similar conversions. The results are similar to the mesoporous silica $\mathrm{pSO}_{3} \mathrm{H}-\mathrm{SBA}-15$ but higher than that obtained for the commercial Nafion SAC-13 (53\%). For the mesoporous carbon catalysts studied, the functional group and support structure do not seem to affect the HMF selectivity. On the other hand, the HMF production turnover frequency (TOF) is affected by the catalyst nature. As shown in Table 2, CMK-3-PSA, CMK-3-NSA, and $\mathrm{pSO}_{3} \mathrm{H}-\mathrm{SBA}-15$ displayed comparable TOF values, which were higher than the TOF obtained for CMK-3-SA and Nafion SAC-13. CMK-5-PSA is the catalyst with highest TOF, being approximately 1.5 and 2 times higher than the TOF obtained for CMK-3-PSA and Nafion SAC-13, respectively. 


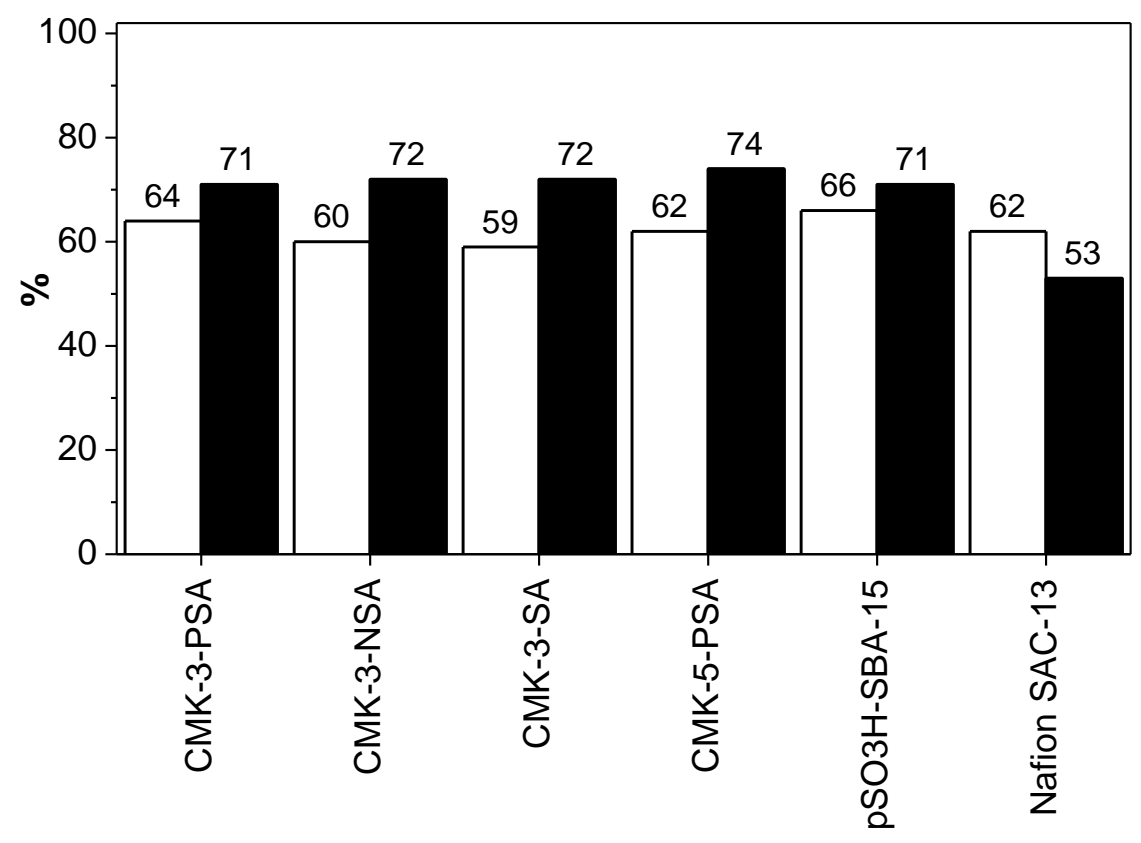

Figure 3.Conversion (white bars) and selectivity (black bars) for the CMK-3 and CMK-5 based catalysts, $\mathrm{pSO}_{3} \mathrm{H}-\mathrm{SBA}-15$, and SAC-13.

The deactivation of the CMK-3 and CMK-5 based catalysts was studied in $1 / 2$ inch diameter downflow reactor at a high flow rate in the kinetic regime, as previously reported.[3, 16] By using a broader reactor than the one used for the activity studies, the bed length decreases, which results in a lower pressure drop and a decreased driving force for liquid channeling [16]. The first order deactivation rate coefficient for each catalyst was obtained by plotting the log of the TOF as a function of the time on stream (Figure 4 and Table 2). Deactivation of the acid mesoporous carbons can take place mainly due to coking or leaching of the active sites [29, 30]. As reported previously [16], at the reaction conditions used, the extent of carbon deposition is minimized and the deactivation is primarily due to leaching of the active sites. In the case of the mesoporous carbons studied, the leaching mechanism is similar to that observed for sulfonated polystyrene resins $[29,30]$, in which the sulfonic acid moiety bonded to the aromatic ring is hydrolyzed to sulfuric acid. 
Table 2. Initial HMF production TOF and first order deactivation rate coefficient for CMK-3 and CMK5 based catalysts, $\mathrm{pSO}_{3} \mathrm{H}-\mathrm{SBA}-15$, and $\mathrm{SAC}-13$.

\begin{tabular}{|c|c|c|}
\hline Catalyst & HMF TOF ${ }^{\mathrm{a}} / \mathrm{min}^{-1}$ & Deactivation Rate Coefficient $^{b} / h^{-1}$ \\
\hline CMK-3-PSA & 0.045 & 0.006 \\
\hline CMK-3-NSA & 0.052 & 0.009 \\
\hline CMK-3-SA & 0.028 & 0.014 \\
\hline CMK-5-PSA & 0.069 & 0.002 \\
\hline $\mathrm{pSO}_{3} \mathrm{H}-\mathrm{SBA}-15$ & 0.048 & 0.120 \\
\hline Nafion SAC-13 & 0.033 & 0.008 \\
\hline
\end{tabular}

${ }^{\text {a }}$ Initial TOF obtained at $\mathrm{X}=0$ obtained from the extrapolation of the curve $\ln (\mathrm{TOF})$ for HMF production as a function of time on stream; ${ }^{b}$ First order deactivation rate coefficient is the slope of the curves shown in Figure 4.

The first order deactivation rate coefficients for all catalysts studied are shown in Table 2 . Comparing the CMK-3 based materials, the stability of the functional groups in the reaction conditions follows the order PSA > NSA> $-\mathrm{SO}_{3} \mathrm{H}$. When comparing the different supports, $\mathrm{CMK}-5$-PSA is more stable than CMK-3-PSA, even though CMK-3 structure is more robust. 


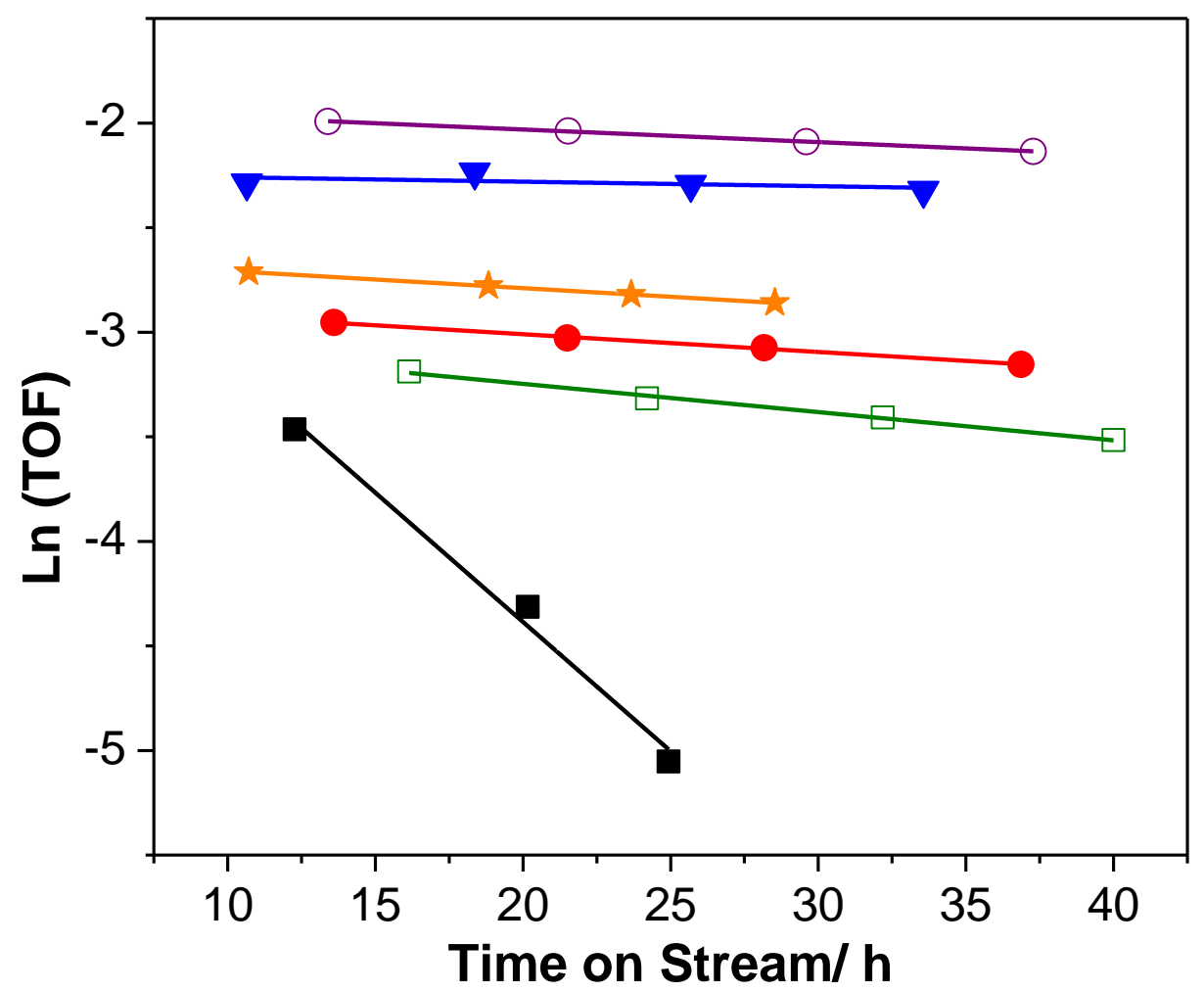

Figure 4. Natural logarithm of the HMF production TOF as a function of the time on stream. (open purple circles) CMK-3-PSA, (full red circles) CMK-3-NSA, (open green squares) CMK-3-SA, (full blue triangles) CMK-5-PSA, (full black squares) SBA-15- $\mathrm{pSO}_{3} \mathrm{H}$, and (full orange stars) Nafion SAC13.

The deactivation rate coefficients for CMK-3-PSA, CMK-3-NSA, CMK-3-SA, and CMK-5-PSA were, respectively, 20, 13.3, 8.5, and 60 times lower than $\mathrm{pSO}_{3} \mathrm{H}-\mathrm{SBA}-15$. The deactivation of $\mathrm{pSO}_{3} \mathrm{H}-$ SBA-15 is due primarily to leaching of the whole functional group $\left[(\mathrm{OH})_{3} \mathrm{Si}(\mathrm{CH} 2)_{3} \mathrm{SO}_{3} \mathrm{H}\right]$ by hydrolysis of the support surface, which is easier than the hydrolysis of the $\mathrm{C}-\mathrm{SO}_{3} \mathrm{H}$ bond [16]. Comparing the acid mesoporous carbons with the commercial Nafion SAC-13, known for its remarkable stability, we observed that the deactivation rate constant for the Nafion catalyst is similar to CMK-3-NSA, and 1.5 and 3 times higher than for CMK-3-PSA and CMK-5-PSA.

\section{Conclusions}

We show that acid mesoporous carbon based catalysts present comparable performance to silica based catalysts in the conversion of fructose to HMF in the presence of water. However, acid mesoporous carbon had a significantly lower deactivation rate coefficient, being up to 60 more stable than pSO3H-SBA-15, and up to three times more stable than the commercial Nafion SAC-13. From the 
catalysts studied, CMK-5-PSA is the most promising material, since it not only presents the lowest deactivation, but also the highest TOF for HMF production. Acid mesoporous carbons have potential to substitute the well-known and well characterized mesoporous silica and organosilica based catalysts, as well as the commercial Nafion SAC-13, for biomass conversion in the presence of water.

\section{Acknowledgements}

This work was supported by NSF under the CCI Center for Enabling New Technologies through Catalysis (CENTC) Phase II Renewal, CHE-1205189. J.M.R.G. acknowledges support by the U.S. Department of Energy under grant number DE-FG02-84ER13183. R.A. acknowledges support by the NSF GRFP under grant number DGE-0718123. The authors also thank Christian Rivera Goyco for help in catalyst preparation.

\section{References}

[1] J.J. Bozell, G.R. Petersen, Green Chem., 12 (2010) 539-554.

[2] T.A. Werpy, G. Petersen, in, U.S. Department of Energy, 2004.

[3] M.H. Tucker, in: Department of Chemical \& Biological Engineering, University of WisconsinMadison, Madison, 2011.

[4] A.J. Crisci, M.H. Tucker, M.Y. Lee, S.G. Jang, J.A. Dumesic, S.L. Scott, ACS Catal., 1 (2011) 719728.

[5] Y. Roman-Leshkov, J.A. Dumesic, Top. Catal., 52 (2009) 297-303.

[6] Y. Roman-Leshkov, J.N. Chheda, J.A. Dumesic, Science, 312 (2006) 1933-1937.

[7] V.V. Ordomsky, J. van der Schaaf, J.C. Schouten, T.A. Nijhuis, J. Catal., 287 (2012) 68-75.

[8] F.S. Asghari, H. Yoshida, Carbohydr. Res., 341 (2006) 2379-2387.

[9] C. Moreau, R. Durand, S. Razigade, J. Duhamet, P. Faugeras, P. Rivalier, P. Ros, G. Avignon, Appl. Catal., A, 145 (1996) 211-224.

[10] H.B. Zhao, J.E. Holladay, H. Brown, Z.C. Zhang, Science, 316 (2007) 1597-1600.

[11] X.H. Qi, M. Watanabe, T.M. Aida, R.L. Smith, Green Chem., 10 (2008) 799-805.

[12] J.M.R. Gallo, D.M. Alonso, M.A. Mellmer, J.A. Dumesic, Green Chem., 15 (2013) 85.

[13] A. Corma, Chem. Rev., 97 (1997) 2373-2419.

[14] R. Rinaldi, F. Schuth, Energ. Environ. Sci., 2 (2009) 610-626.

[15] M.H. Tucker, in: Chemical and Biological Engineering, University of Wisconsin-Madison, 2011.

[16] M.H. Tucker, A.J. Crisci, B.N. Wigington, N. Phadke, R. Alamillo, J.P. Zhang, S.L. Scott, J.A. Dumesic, ACS Catal., 2 (2012) 1865-1876.

[17] K. Suwannakarn, E. Lotero, J.G. Goodwin, C.Q. Lu, J. Catal., 255 (2008) 279-286.

[18] J.M. Anderson, R.L. Johnson, K. Schmidt-Rohr, B.H. Shanks, Carbon, 74 (2014) 333-345.

[19] M. Kruk, M. Jaroniec, T.W. Kim, R. Ryoo, Chem. Mater., 15 (2003) 2815-2823.

[20] S. Jun, S.H. Joo, R. Ryoo, M. Kruk, M. Jaroniec, Z. Liu, T. Ohsuna, O. Terasaki, J. Am. Chem.

Soc., 122 (2000) 10712-10713.

[21] X.Q. Wang, R. Liu, M.M. Waje, Z.W. Chen, Y.S. Yan, K.N. Bozhilov, P.Y. Feng, Chem. Mater., 19 (2007) 2395-2397. 
[22] R. Xing, Y.M. Liu, Y. Wang, L. Chen, H.H. Wu, Y.W. Jiang, M.Y. He, P. Wu, Microporous Mesoporous Mater., 105 (2007) 41-48.

[23] A.J. Crisci, M.H. Tucker, J.A. Dumesic, S.L. Scott, Top. Catal., 53 (2010) 1185-1192.

[24] G. Rajagopal, H. Lee, S.S. Kim, Tetrahedron, 65 (2009) 4735-4741.

[25] M.H. Tucker, R. Alamillo, A.J. Crisci, G.M. Gonzalez, S.L. Scott, J.A. Dumesic, ACS Sustainable Chemistry \& Engineering, 1 (2013) 554-560.

[26] L.M. Yang, Y.J. Wang, G.S. Luo, Y.Y. Dai, Microporous Mesoporous Mater., 84 (2005) 275-282.

[27] H. Darmstadt, C. Roy, S. Kaliaguine, T.W. Kim, R. Ryoo, Chem. Mater., 15 (2003) 3300-3307.

[28] S.H. Joo, S.J. Choi, I. Oh, J. Kwak, Z. Liu, O. Terasaki, R. Ryoo, Nature, 412 (2001) 169-172.

[29] J.M. Aragon, J.M.R. Vegas, L.G. Jodra, Ind. Eng. Chem. Res., 33 (1994) 592-599.

[30] L. Petrus, E.J. Stamhuis, G.E.H. Joosten, Industrial \& Engineering Chemistry Product Research and Development, 20 (1981) 366-371. 